\title{
Estudo do processo de gramaticalização do verbo poder no dialeto mineiro: análise comparativa entre o dialeto belo-horizontino e o dialeto ouro-pretano
}

Study of the process of grammaticalization of the verb "poder" in the dialect of Minas Gerais: comparative analyses between the dialects of Belo Horizonte and Ouro Preto

\author{
Sueli Maria Coelho \\ Universidade Federal de Minas Gerais \\ Thaís Franco de Paula \\ Universidade Federal de Ouro Preto
}

Resumo

Estudou-se, numa perspectiva pancrônica, o processo de gramaticalização do verbo PODER no dialeto mineiro. Com base em uma metodologia quantitativa de estudo da gramaticalização, buscou-se investigar o fenômeno linguístico responsável pela erosão fonética da referida forma verbal quando esta se junta à forma nominal de infinitivo para formar uma perífrase, conforme se observa em "po' falá", "po' de(i)xá", "po' fazê". Partiu-se da hipótese de que tal redução está associada ao estágio avançado do processo de gramaticalização dessa forma verbal. Os resultados obtidos confirmaram a hipótese aventada e demonstraram ainda que, desde o século XVIII, tal verbo é empregado, no falar mineiro, prioritariamente em sua função gramatical. 


\section{Palavras-Chave}

Gramaticalização, Verbo PODER, Forma lexical, Forma gramatical, Dialeto mineiro.

\section{Abstract}

In a panchronic perspective, the grammaticalization of the verb "poder" (can) is analyzed in the dialect of Minas Gerais. Starting from a quantitative method of studying the grammaticalization, we have investigated the linguistic phenomenon responsible for the phonetic reduction of this verbal form, when it is linked to the infinitive to form a periphrasis, as observed in "po' falá", "po' de(i)xá", "po' fazê". The hypothesis is that this reduction is a consequence of its advanced stage of grammaticalization. The results obtained confirmed this hypothesis and also demonstrated that this verb, in the dialect of Minas Gerais, has been preferably used in its grammatical form since the XVIII century.

\section{Keywords}

Grammaticalization, Verb “poder”, Lexical form, Grammatical form, Minas Gerais dialect. 


\section{Considerações iniciais}

uem nunca ouviu alguém dizer maliciosamente que o mineiro é

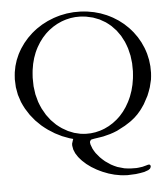
preguiçoso para falar, dado que tem o costume de suprimir partes de palavras, especialmente o seu final? Esse tipo de preconceito contra o modo de falar do povo mineiro tem gerado não só constrangimento a muitos falantes desse dialeto, como também despertado o interesse de vários linguistas que se dedicam ao estudo do falar dessa região, no intuito de descrevê-lo cientificamente e de desmitificar muitos desses estereótipos que traduzem o senso comum. ${ }^{1}$ A pesquisa aqui descrita representa mais um esforço nesse sentido e elegeu como objeto de estudo a erosão fonética do verbo PODER $\left(p o^{\prime}\right)$ quando este constitui locuções verbais no dialeto mineiro, resultando em construções como po'fazê, po’ pô pó, po’ de(i)xá..., que tantas críticas rendem ao povo mineiro, fazendo-o, inclusive, alvo de inúmeras piadas. Dessa forma, a investigação teve por fito empreender um estudo de natureza pancrônica acerca do processo de gramaticalização ${ }^{2}$ do verbo PODER no falar mineiro, traçando uma comparação entre o dialeto empregado na capital e aquele empregado em Ouro Preto, um dos mais antigos núcleos populacionais do estado de Minas Gerais. Partiu-se da hipótese de que a erosão fonética dessa forma verbal manifesta tão naturalmente nos dados do falar mineiro tem uma causa linguística e não social, ou seja, acredita-se que tal erosão retrata um estágio avançado do processo de recategorização do verbo pleno em forma gramatical, decorrendo, portanto, de seu processo de gramaticalização em auxiliar de modalidade. Tal crença é oriunda do fato de semelhante erosão não poder ser constatada na forma plena do verbo, bem como de haver algumas restrições contextuais a interferir na erosão fonética da forma gramatical, conforme se propõem a ilustrar estes enunciados:

(a) * Ninguém po' com esse menino levado.

(b) Ninguém po' dize(r) que ele não estava avisado. 
(c) A criança não po' viaja(r) sem a autorização dos pais.

(d) * A criança não po' i(r) sozinha ao cinema.

A opção por um estudo de natureza pancrônica deveu-se à natureza sintática do fenômeno, dado ser a sintaxe o estrato linguístico em que as mudanças se processam mais lentamente. Em virtude disso, o estudo da mudança linguística foi feito em tempo real, ou seja, comparando-se dados dos séculos XVIII, XIX e XXI.

A pesquisa empreendida tomou como objeto de análise e de descrição linguística os dialetos ouro-pretano e belo-horizontino, visando a investigar as seguintes questóes-problema: (i) a erosão fonética do verbo PODER em formas perifrásticas (ou locuções verbais) do dialeto mineiro caracteriza uma redução própria da gramaticalização dessa forma verbal ou é apenas fruto de uma tendência linguística característica dessa região?; (ii) a erosão fonética ora descrita ocorre com qualquer forma principal ou existem aquelas que a favorecem ou que a impedem?; (iii) que fatores (fonéticos, sintáticos ou morfológicos) interferem numa possível seleção das formas que se reduzem e naquelas que não se reduzem?; (iv) qual o papel dessa forma verbal na expressão da modalidade linguística do falar mineiro?

A realização desta pesquisa, além de contribuir para a descrição científica do dialeto mineiro, delineando a sua história social, constitui também uma possibilidade potencial de agregação de conhecimento para a área da variação e mudança linguística, bem como para os estudos de gramaticalização de itens em Língua Portuguesa. Os dados obtidos com o estudo do dialeto mineiro nos três séculos contemplados por este estudo poderão ser confrontados não apenas com outros períodos da história da Língua Portuguesa, como também com falares de outras regiōes, o que certamente contribuirá para a elucidação da hipótese aventada e também para a descrição do processo de gramaticalização do modal PODER. Há de se assinalar que os dados aqui obtidos suscitam também novas questôes e são, portanto, potencialmente fontes de outros estudos, o que, espera-se, fomentará novas investigações, alimentando o ciclo de pesquisas linguísticas. 


\section{O dinamismo linguístico e o fenômeno da gramaticalização}

Ao contrário do que pensam os falantes, a língua não é uma realidade estática; ela se encontra em constante transformação, o que pode desencadear variações que virão ou não a se converter em mudança linguística. As categorias linguísticas não constituem, portanto, realidades estáveis e, ao longo da história, categorias lexicais podem passar a funcionar como categorias gramaticais, fenômeno denominado metalinguisticamente de gramaticalização.

A despeito de haver, já no final do século XIX, uma tradição nos estudos acerca da gramaticalização de itens linguísticos, o termo gramaticalização foi empregado pela primeira vez em 1912, pelo linguista francês Antoine Meillet. Para esse estudioso de questões linguísticas, a gramaticalização é um fenômeno de transição gradual entre categorias cujo estudo deve ser diacrônico, já que o que está em questão numa perspectiva linguística mais científica não são as origens das formas gramaticais, mas suas transformaçōes. Além de nomeá-la e de precisarlhe os limites, esse linguista postulou ainda o primado da gramaticalização sobre a analogia - muito valorizada entre os neogramáticos -, ao afirmar que esta apenas pode operar quando um núcleo de formas já tenha emergido, descartando a possibilidade de ela constituir uma fonte primária de novas formas gramaticais. Estava assim lançado um novo objeto de pesquisa linguística, o qual passou a despertar o interesse de inúmeros pesquisadores que até hoje se debruçam sobre fenômenos dessa natureza no intuito de extrair deles implicações teóricas capazes de explicar alguns processos de variação e mudança linguística.

Nessa esteira, Lehmann (1982) propôs que os fenômenos de gramaticalização de itens linguísticos são regidos por cinco princípios: paradigmatização, obrigatoriedade, condensação, coalescência e fixação. A paradigmatização é definida pela tendência que as formas apresentam para se organizarem em paradigmas mais ou menos reduzidos e homogêneos. A obrigatoriedade relaciona-se intimamente à paradigmatização, uma vez que, dentro do paradigma, a escolha entre os membros não se dá aleatoriamente, mas obedece a determinadas regras. À medida que o item se gramaticaliza, nota-se ainda uma condensação de sua forma, que tende a se tornar mais curta. Esse é um dos princípios que parece atuar diretamente sobre o objeto deste estudo. A coalescência, também denominada aglutinação, resulta da justaposição de formas adjacentes; de um processo metonímico, portanto. Por fim, a fixação, entendida como a tendência apresentada pelas ordens linearmente livres a se tornarem presas, num estágio já avançado do processo. 
Enquanto Lehmann (1982) postula seus princípios tomando por base um processo prototípico de gramaticalização, Hopper (1991) o faz pautando-se no caráter gradual do fenômeno, uma vez que os princípios da estratificação, da divergência, da especialização, da persistência e da descategorização propostos por ele respondem à questão do "mais" ou "menos" gramatical. A estratificação baseiase, segundo o autor, na constante emergência de novas formas que, não suplantando as velhas, passam a coexistir com elas, numa perspectiva de mudança que se distingue da laboviana. A divergência pode, no entendimento do autor, ser analisada como um caso particular de estratificação por também implicar certa convivência de formas: quando há a gramaticalização de uma forma lexical, a forma original pode permanecer ainda como elemento autônomo, sujeito, portanto, às mesmas mudanças que os itens lexicais não gramaticalizados. Tanto a especialização quanto a persistência são influenciadas pelas alterações semânticas que envolvem o fenômeno da gramaticalização. A primeira diz respeito à possibilidade de escolha determinada pelas diferentes nuanças semânticas, enquanto a segunda se refere à persistência de vestígios do significado lexical primitivo, muitas vezes refletido nas restrições sobre o comportamento gramatical do item. O último princípio, a descategorização, associa-se diretamente ao surgimento de formas híbridas oriundas da redução do estatuto categorial dos itens gramaticalizados. Tais princípios, contudo, foram reformulados por Hopper e Traugott (1993), em decorrência da adoção de um único princípio fundamental: o princípio da unidirecionalidade, segundo o qual existe uma relação intrínseca e linear entre os estágios do processo de gramaticalização, de modo que um estágio anterior não pode preceder o anterior. Tal princípio fundamental tornase, dessa forma, uma hipótese verificável por meio da atuação dos mecanismos envolvidos no processo. Nessa nova perspectiva, os antigos princípios passam a ser tratados, então, como processos constitutivos do fenômeno da gramaticalização.

Além dos princípios/mecanismos que atuam no processo de gramaticalização, há também os estágios potenciais de um item/construção que se desloca da categoria lexical para a gramatical. Segundo propõe Castilho (1997), com base em uma releitura de Lehmann (1982), um processo de gramaticalização compreende os seguintes estágios: sintatização, morfologização, redução fonológica e estágio zero. A sintatização de um item lexical é a fase em que este item é recategorizado, ou seja, muda de categoria lexical para categoria gramatical. A morfologização consiste na criação de formas presas, podendo estas ser morfemas flexionais ou mesmo derivacionais. A redução fonológica é um processo que ocorre sempre que há a 
fusão de formas livres em formas presas, que se gramaticalizam como afixos. Por fim, o estágio zero retrata o momento máximo de exaustão da estrutura e indica a retomada da gramaticalização, que é um processo cíclico.

Trilhando também o percurso de um item em processo de gramaticalização, Coelho (2006) constatou que, ao se gramaticalizar, uma forma linguística sofre algumas modificações que podem ser tomadas pelo pesquisador como um instrumental de análise para identificar se o que se suspeita ser um fenômeno de gramaticalização de fato o é. Segundo a autora, a primeira dessas mudanças é a alteração semântica, que decorre de uma perda gradual do conteúdo nocional do item para incorporação de conteúdo gramatical. Outra característica do processo é o aumento da frequência do item, pois ele, segundo prevê o princípio da estratificação, passa a desempenhar funçōes tanto gramaticais quanto lexicais, o que amplia seus contextos linguísticos de ocorrência. A especialização dos contextos sintáticos em que o item pode ocorrer é outra evidência de gramaticalização. Tal especialização pode ser identificada, segundo Lehmann (1982), tanto pela análise da coesão sintagmática quanto pela observação da variabilidade sintagmática, já que a posição fixa do item dentro do paradigma constitui um indício do aumento de sua gramaticalidade. Outra característica que contribui para a investigação do fenômeno e que se relaciona diretamente à pesquisa empreendida é a redução do material fônico do item, favorecida não só pelo aumento de sua frequência de uso, como também pela perda de seu conteúdo nocional, consequência de seu processo de abstração.

\section{Descrição dos critérios metodológicos adotados}

\subsection{Caracterização dos corpora}

Como já anunciado, esta pesquisa, traçando uma comparação entre o dialeto empregado hoje na capital mineira e aquele empregado em Ouro Preto, um dos mais antigos núcleos populacionais do estado de Minas Gerais, empreendeu um estudo de natureza pancrônica acerca do processo de gramaticalização do verbo PODER no dialeto mineiro. Para tanto, procedeu-se, inicialmente, à seleção e à constituição dos corpora, os quais foram compostos tanto por textos escritos (séculos XVIII e XIX) quanto por textos orais (século XXI). ${ }^{3}$

$\mathrm{O}$ corpus da região de Ouro Preto representativo do século XVIII constituise de 26 documentos do Fundo Barão de Camargos, compreendendo uma 
relativa diversidade de gêneros textuais: correspondências, bilhetes emitidos, quitação de bens, certidão de banhos, ${ }^{4}$ escritura de venda de casa e carta de alforria. $\mathrm{O}$ corpus representativo do século XIX, ainda da mesma região, compõese de cartas pessoais integrantes do Acervo Histórico Monsenhor Horta, localizado no Instituto de Ciências Humanas e Sociais, da Universidade Federal de Ouro Preto (MG). Já os corpora representativos do século XXI pertencem à modalidade oral da língua e se compõem de transcrições de entrevistas gravadas com falantes de Ouro Preto e de Belo Horizonte. Na medida do possível, buscou-se privilegiar, na constituição do corpus, a diversidade de gêneros textuais, critério recomendado para se tentar flagrar o maior número possível de ocorrências do item estudado em seus mais diversos contextos de realização.

A pesquisa empreendida foi de natureza quantitativa. A opção por um estudo de tal natureza se deve à recomendação de estudiosos do fenômeno, entre os quais se destaca Vitral (2005), para quem apenas o apelo a uma metodologia quantitativa possibilita ao linguista pesquisador diagnosticar de forma precisa e segura processos de gramaticalização, "já que os procedimentos usuais de identificação desses processos são dependentes da intuição do falante/pesquisador e nem sempre são aplicáveis a fenômenos para os quais se suspeita estar ocorrendo um processo desse tipo." (p. 1)

Considerando-se o caráter quantitativo do estudo, na medida do possível, zelou-se também para que houvesse certo equilíbrio de tamanho entre os corpora representativos de cada um dos séculos estudados, a fim de minimizar o favorecimento de ocorrência acentuada do verbo PODER em determinado período, o que poderia falsear os dados obtidos. Assim, foi necessário proceder a recortes nos corpora, os quais foram feitos mantendo-se a coerência do texto. Feitos tais ajustes, as amostras linguísticas de cada período/região ficaram assim constituídas:

\begin{tabular}{c|c}
\hline IDENTIFICAÇÃO DOS CORPORA & NúMERO DE PALAVRAS CONSTITUINTES \\
\hline séc. XVIII (Ouro Preto) & 6.701 palavras \\
séc. XIX (Ouro Preto) & 6.986 palavras \\
séc. XXI (Ouro Preto) & 7.606 palavras \\
séc. XXI (Belo Horizonte) & 7.196 palavras \\
\hline
\end{tabular}

Total da amostra: 28.489 palavras 


\subsection{Definição dos critérios de análise}

Embasando-se nas modificações por que passam os itens/construções em processo de gramaticalização, as quais foram descritas na segunda seção deste trabalho, e também na metodologia quantitativa desenvolvida por Vianna (2000) e aperfeiçoada por Vitral (2005) e por Coelho (2006), subdividiram-se os critérios de análise em dois grupos interdependentes. O primeiro deles visa a quantificar o processo de gramaticalização do verbo PODER, recorrendo-se, para tanto, à análise da sua frequência. $\mathrm{O}$ segundo grupo de critérios, que também foi analisado quantitativamente, atém-se ao estudo de fatores semânticos, sintáticos e fonéticos envolvidos no processo de gramaticalização do verbo selecionado para este estudo.

\section{Apresentação e discussão dos dados}

A análise e a discussão dos dados obtidos nesta pesquisa serão apresentadas observando-se os critérios de gramaticalização descritos na seção ulterior. Nesse sentido, inicialmente analisar-se-á a frequência total do verbo em estudo, bem como sua frequência como forma lexical e forma gramatical, ao longo das três sincronias delimitadas. Em seguida, proceder-se-á à análise dos critérios semânticos, observando-se as diferentes modalidades expressas pelo verbo PODER. Dando continuidade à análise, serão apresentados os dados referentes ao critério sintático, com o qual se visa a observar a variabilidade sintagmática do verbo em questão e também o grau de coesão da perífrase ao longo dos três séculos. Finalmente, pautando-se por critério fonético, analisar-se-ão os contextos de erosão fonética do verbo PODER quando este se junta à forma nominal de infinitivo para constituir perífrases modais.

\subsection{Análise da frequência do verbo PODER}

A análise da frequência do item buscou detectar se, diacronicamente, houve um aumento da frequência total da forma em análise, dado que, ao se gramaticalizar, ela passa a ser empregada tanto na categoria dos itens lexicais como na categoria dos itens gramaticais. No caso específico deste estudo, computou-se como forma lexical a forma simples do verbo e, como forma gramatical, sua forma auxiliar, que coocorre com o infinitivo, formando perífrases 
modais. Contudo, há de se advertir que o mero aumento da frequência total do item não é suficiente para atestar a sua gramaticalização. Para tanto, faz-se necessário que esse aumento se concentre em seus usos gramaticais, opondo-se ao decréscimo de seus usos lexicais, aspecto que justifica a computação do item em suas duas formas.

Visando a obter tais valores, procedeu-se, então, à contagem das formas do verbo $P O D E R$, em todas as suas flexôes. Essa contagem foi realizada em cada um dos três séculos selecionados para o estudo, obtendo-se, assim, a frequência total da forma por século. Para encontrar a porcentagem dessas ocorrências em relação ao número total de palavras representativas do século, recorreu-se a uma regra de três simples. Feito isso, passou-se à separação de cada uma das ocorrências verbais cotejadas, selecionando-as em formas lexicais e em formas gramaticais. Mais uma vez, recorreu-se à regra de três simples para identificar a porcentagem de ocorrência de cada uma dessas formas. Os dados obtidos foram tabulados e a quantificação das ocorrências está apresentada na tabela 1 .

TABELA 1

Análise diacrônica da frequência do verbo PODER no falar mineiro

\begin{tabular}{|c|c|c|c|c|c|c|c|c|c|c|c|c|c|c|c|}
\hline \multirow{2}{*}{\multicolumn{4}{|c|}{$\frac{\text { SÉCULO XVIII }}{\text { Ouro Preto }}$}} & \multirow{2}{*}{\multicolumn{4}{|c|}{$\frac{\text { SÉCULO XIX }}{\text { Ouro Preto }}$}} & \multicolumn{8}{|c|}{ SÉCULO XXI } \\
\hline & & & & & & & & & Duro & Preto & & & elo $\mathrm{H}$ & rizon & \\
\hline \multicolumn{4}{|c|}{ Frequência total } & \multicolumn{4}{|c|}{ Frequência total } & \multicolumn{4}{|c|}{ Frequência total } & \multicolumn{4}{|c|}{ Frequência total } \\
\hline \multicolumn{2}{|c|}{$\begin{array}{c}\text { No de } \\
\text { ocorrências }\end{array}$} & \multicolumn{2}{|c|}{$(\%)$} & \multicolumn{2}{|c|}{$\begin{array}{c}\text { No de } \\
\text { ocorrência }\end{array}$} & \multicolumn{2}{|c|}{$(\%)$} & \multicolumn{2}{|c|}{$\begin{array}{c}\text { No de } \\
\text { ocorrência }\end{array}$} & \multicolumn{2}{|c|}{$(\%)$} & \multicolumn{2}{|c|}{$\begin{array}{c}\text { No de } \\
\text { ocorrências }\end{array}$} & \multicolumn{2}{|c|}{$(\%)$} \\
\hline \multicolumn{2}{|c|}{17} & \multicolumn{2}{|c|}{0,25} & \multicolumn{2}{|c|}{20} & \multicolumn{2}{|c|}{0,28} & \multicolumn{2}{|c|}{31} & \multicolumn{2}{|c|}{0,} & \multicolumn{2}{|c|}{2} & \multicolumn{2}{|c|}{0,3} \\
\hline \multicolumn{2}{|c|}{$\begin{array}{l}\text { Frequência } \\
\text { Lexical }\end{array}$} & \multicolumn{2}{|c|}{$\begin{array}{l}\text { Frequência } \\
\text { Gramatical }\end{array}$} & \multicolumn{2}{|c|}{$\begin{array}{c}\text { Frequência } \\
\text { Lexical }\end{array}$} & \multicolumn{2}{|c|}{$\begin{array}{l}\text { Frequência } \\
\text { Gramatical }\end{array}$} & \multicolumn{2}{|c|}{$\begin{array}{c}\text { Frequência } \\
\text { Lexical }\end{array}$} & \multicolumn{2}{|c|}{$\begin{array}{l}\text { Frequência } \\
\text { Gramatical }\end{array}$} & \multicolumn{2}{|c|}{$\begin{array}{l}\text { Frequência } \\
\text { Lexical }\end{array}$} & \multicolumn{2}{|c|}{$\begin{array}{l}\text { Frequência } \\
\text { Gramatica }\end{array}$} \\
\hline Oc. & (\%) & Oc & (\%) & Oc & $(\%)$ & Oc. & $(\%)$ & Oc. & (\%) & Oc. & $(\%)$ & Oc. & $(\%)$ & Oc. & $(\%)$ \\
\hline 0 & 0 & 17 & 100 & 1 & 5 & 19 & 95 & 0 & 0 & 31 & 100 & 0 & 0 & 23 & 100 \\
\hline
\end{tabular}

Fonte: Dados coletados.

Conforme se observa na tabela 1 , no século XVIII, não foram encontradas, no corpus analisado, ocorrências de formas lexicais, o que indica que, nesse período, o verbo PODER já era empregado apenas como forma gramatical. Esse dado comunga com estudos empreendidos por outros pesquisadores para a 
mesma forma verbal. Ferreira (2000), após analisar amostras de três sincronias bastante pregressas - século II a.C., século XVI e século XX -, chegou à conclusão de que o processo de gramaticalização do verbo PODER em construções com o infinitivo remonta às origens do português, estando, portanto, já bastante consolidado. Diante de tal quadro de estabilização de mudança, não se esperava mais um aumento crescente na frequência do item, o que foi confirmado pelos dados analisados.

A única ocorrência de PODER lexical identificada no corpus foi registrada no século XIX:

(1) "[...] ficando obrigado o dito comprador a pagar os direitos naceonais, e nos afazer esta venda sua em todo tempo que duvida haja e por verdade do refirido pode Florenttino Gonçalves Jacob que esta escreve e nos só asignamos com estes testemunha presentes" (Ouro Preto, século XIX, grifo nosso).

Tal registro, contudo, não descaracteriza a mudança categorial atestada pela totalidade de ocorrências gramaticais registrada no século anterior. Há de se considerar que, conforme prevê o princípio da estratificação, a gramaticalização não requer concorrência de formas, mas admite a sua coexistência em categorias distintas. Além disso, segundo comenta Ferreira (op. cit.), a literatura aponta que "os sentidos diacronicamente mais antigos tendem a ser conservados por mais tempo em contextos negativos, mais conservadores no que diz respeito à mudança linguística" (p. 86). No caso da pesquisa empreendida por ela, as ocorrências de PODER lexical, isto é, não seguido de infinitivo e dotado de referenciação extralingüística, não apenas confirmaram a previsão da literatura, como também se mostraram bastante fossilizadas, ocorrendo em contexto sintático bem definido: seguido de sintagma preposicional ("Não posso com altura"). No caso de Minas Gerais, entretanto, a forma lexical, conforme demonstra (1), ocorre em contexto afirmativo, que costuma ser mais inovador. ${ }^{5}$ Isso pode sinalizar uma maior resistência à mudança e um consequente conservadorismo, mas uma afirmativa categórica a esse respeito extrapola os limites do estudo aqui realizado.

\subsection{Análise de aspectos semânticos do verbo PODER}

Coelho (2006) avalia que a análise de aspectos semânticos é, 
sem dúvida, o critério que maior empecilho oferece à análise quantitativa proposta, dada a dificuldade de se quantificar, de maneira precisa, as várias nuanças semânticas que um item passa a assumir não apenas em um mesmo período, como também em períodos diversos. Segundo prevê a literatura, à medida que o item entra em processo de gramaticalização, ele sofre alterações semânticas, pois existe uma tendência de seus usos irem se tornando cada vez mais abstratos até atingirem um grau máximo de abstração, esvaziandose de seu sentido original para assumir funçôes gramaticais. Os teóricos da gramaticalização acreditam que, num estágio consolidado do processo, há uma sobreposição dos usos abstratos em relação aos usos concretos, porque o processo metafórico envolvido no fenômeno da gramaticalização prevê a tramitação do item do [+ concreto] para $\mathrm{o}$ [+ abstrato], à medida que este se distancia de suas funções lexicais para incorporar funções gramaticais (p.114).

Esse processo de abstração é percebido de forma mais substancial na passagem de forma lexical para forma gramatical. Dado que, conforme atestaram os índices de frequência, no falar mineiro - e também na língua portuguesa, conforme dados de Ferreira (2000) -, o verbo PODER já se encontra tão gramaticalizado que basicamente se restringe às locuções verbais, forma gramatical, portanto, esperava-se que, nesse contexto, seu grau de abstração fosse tamanho que já não fosse possível identificar traços de seu conteúdo lexical, como ocorre com os auxiliares prototípicos. No entanto, o que se constatou foi que, segundo prevê o princípio da persistência, proposto por Hopper (1991), os resquícios de seu conteúdo nocional ainda são sentidos na expressão da modalidade linguística, aspecto que se passa agora a analisar e que pode constituir um traço característico do processo de gramaticalização dos modais, assim como os há para a gramaticalização de verbos nocionais e de verbos relacionais. ${ }^{6}$

Desde os estudos clássicos, a modalidade ocupa um papel de destaque nos estudos semânticos. Segundo Koch (1997), "um mesmo indicador modal pode ser veiculado sob modalidades diferentes" (p.47). Costa (2009), embasada em teóricos como Sweetser (1990), Coates (1995), Givón (2001) e Traugott; Dasher (2005), afirma que, além da categoria de modo, alguns verbos auxiliares são também recursos gramaticais para a expressão da modalidade, o que lhes confere a denominação de modais. Esclarece essa autora que a modalidade se manifesta 
na interação verbal, para dar conta dos propósitos comunicativos dos interlocutores. Assim sendo, o contexto torna-se peça indispensável para se interpretar o quanto de comprometimento há por parte do falante/escrevente em relação ao que é dito/ escrito. Há de se assinalar, porém, que mesmo o contexto se mostra, às vezes, limitado para precisar a modalidade, fato que leva alguns autores, como Sweetser (apud COSTA, 2009), a considerarem os verbos modais ambíguos, em virtude de ora se relacionarem ao mundo deôntico, ora ao mundo epistêmico. ${ }^{7}$

Dadas as três possibilidades de leitura modal do verbo que nos ocupa neste estudo, quais sejam, deôntica, epistêmica e deôntica/epistêmica, computou-se, usando regra de três simples, a porcentagem de cada tipo de modalidade nos três séculos estudados. Consideraram-se como valores deônticos do verbo PODER aqueles que traduzem capacidade, habilidade ou permissão, conforme ilustra o enunciado (2) extraído do corpus, e como valores epistêmicos aqueles relacionados à expressão de crença ou possibilidade, conforme ocorrência em (3).

(2) “Cê po’ levá quem cê quisé." (Belo Horizonte, século XXI, grifo nosso)

(3) "[...] um dinheiro que pode ser investido em coisas que pode ser autosustentáveis, né?” (Belo Horizonte, século XXI, grifo nosso).

A análise das ocorrências do verbo PODER no corpus do dialeto mineiro mostrou não apenas que esse verbo é empregado majoritariamente para marcar a modalidade linguística, como também que enquanto, em alguns casos, ele está claramente em contexto deôntico ou em contexto epistêmico, em outros, conforme constataram os autores já citados, mesmo em face do contexto de produção do enunciado, existe a possibilidade de serem-lhe atribuídas as duas interpretaçóes, como ilustra este trecho de uma declaração de venda de terra que diz respeito à efetivação de um negócio:

(4) “[...] nem nós nem nossos herdeiros poderão reclamar por ser feita de nossa livre e espontania vontade [...]” (Ouro Preto, século XIX, grifo nosso).

É possível atribuir duas interpretações diferentes ao posicionamento do enunciador diante do objeto de seu dizer:

(4') Nem nós nem nossos herdeiros teremos a possibilidade de reclamar, pois não há motivos para reclamações, já que fizemos o negócio de livre e espontânea vontade. 
(4") Nem nós nem nossos herdeiros teremos a permissão de reclamar, já que fizemos o negócio de livre e espontânea vontade.

Essa possibilidade de uma dupla interpretação não se dissipa com o avançar do tempo e persiste no século XXI, conforme se verifica neste excerto do corpus oral:

(5) Você citou Augusto dos Anjos. Versos íntimos é o poema-título dele. Pode recitar? (Belo Horizonte, século XXI, grifo nosso).

Esse contexto, assim como o do século XVIII, suporta uma leitura epistêmica (cf. 5') e outra deôntica (cf. 5"), segundo demonstra a argumentação a seguir:

(5’) Você citou Augusto dos Anjos. Versos íntimos é o poema-título dele. Há então a possibilidade de você recitar algum de seus poemas? $(\mathrm{O}$ entrevistador conclui/ infere, com base na evidência de o entrevistado ter citado Augusto dos Anjos, que o entrevistado saiba recitar um poema desse autor).

(5") Você citou Augusto dos Anjos. Versos íntimos é o poema-título dele. Você é capaz de recitar algum de seus poemas? ( $\mathrm{O}$ entrevistador quer saber se o entrevistado tem a capacidade/habilidade de recitar o poema).

Coates (1995 apud COSTA, 2009), divergindo da postura de interpretação ambígua proposta por Sweetser, afirma que, quando uma mesma forma linguística expressa tanto a modalidade deôntica quanto a epistêmica, é comum surgirem instâncias de fusão. Nesse caso, não se estaria diante de um caso de ambiguidade, mas de uma sobreposição de funções, o que atesta a multifuncionalidade do verbo. A facilidade com que o verbo PODER se adapta às mais variadas situações nas amostras analisadas parece constituir um dado a favor de sua classificação como modal multifuncional. Tal multifuncionalidade encontra-se quantificada na tabela 2 : 
TABELA 2

Distribuição das ocorrências de PODER segundo o tipo de modalidade

\begin{tabular}{c|c|c|c}
\hline Regiáo / século & Tipo de Modalidade & $\begin{array}{c}\text { No de } \\
\text { Ocorrências }\end{array}$ & $\begin{array}{c}\text { Ocorrência } \\
\text { em } \%\end{array}$ \\
\hline Ouro Preto / XVIII & Deôntica & 2 & 13,3 \\
& Epistêmica & 10 & 66,7 \\
& Deôntica/Epistêmica & 3 & 20,0 \\
& Total & 15 & 100,0 \\
\hline Ouro Preto / XIX & Deôntica & 3 & 17,6 \\
& Epistêmica & 13 & 76,4 \\
& Deôntica/Epistêmica & 1 & 6,0 \\
& Total & 17 & 100,0 \\
\hline Ouro Preto / XXI & Deôntica & 19 & 70,4 \\
& Epistêmica & 8 & 29,6 \\
& Deôntica/Epistêmica & 0 & - \\
& Total & 27 & 100,0 \\
\hline Belo Horizonte / XXI & Deôntica & 1 & 8,3 \\
& Epistêmica & 9 & 75,0 \\
& Deôntica/Epistêmica & 2 & 16,7 \\
& Total & 12 & 100,0 \\
\hline
\end{tabular}

Fonte: Dados coletados.

Tentando-se uma interpretação desses dados à luz da unidirecionalidade da mudança semântica, isto é, considerando-se o deslizamento do [+ concreto] para [+ abstrato], esperava-se, ao longo dos três séculos, uma redução dos usos da modalidade deôntica [+ concreta] seguida de um aumento da frequência da modalidade epistêmica [+ abstrata]. Os percentuais da tabela 2 comprovam parcialmente essa expectativa, pois tal sobreposição só não é constatada no falar da região de Ouro Preto no século atual. O fato de não sê-lo, ainda que em uma única região - e isso é relevante para o estudo, dado que essa é a única região passível de análise em três sincronias -, atesta que a hipótese do isomorfismo entre as relações polissêmicas sincrônicas e um possível desenvolvimento diacrônico é, conforme vêm defendendo alguns pesquisadores que também adotam perspectivas pancrônicas de análise (cf. VOTRE, 1999; 2000; FERREIRA, 2000; e outros), de fato, problemática. Ferreira (2010) comenta que, muitas vezes, quando se analisam as relações sincrônicas entre itens polissêmicos, "o que se observa é a estabilidade das configurações semântico-sintáticas e não a 
mudança” (p. 235). E, citando Votre (2000), a autora complementa: "estamos tão acostumados à tradição histórico-comparativa e neogramática, que privilegia a mudança, que quase perdemos a capacidade de examinar o estável, o permanente, o duradouro" (FERREIRA, 2010, p. 235).

Outra generalização extraída desses dados diz respeito à multifuncionalidade do verbo, cujos índices mais altos se concentram no século XVIII (20\%). Enquanto, no falar ouro-pretano se registra uma queda gradual nesse índice ao longo dos séculos estudados, no falar belo-horizontino, registrou-se, no século atual, um índice percentual de multifuncionalidade próximo daquele registrado no falar mineiro no século XVIII (16,7\%). Tal distinção tanto pode ser influenciada pela amostragem quanto pode sinalizar um traço distintivo entre os falares dos dois núcleos mineiros. A análise empreendida permitiu ainda uma tentativa de delimitação das principais acepções modais de PODER. Conforme demonstra o gráfico a seguir, nota-se uma tendência de uso desse verbo para traduzir, respectivamente, possibilidade (modalidade epistêmica), permissão e capacidade, sentidos que se relacionam à expressão da modalidade deôntica. Embora esta configure um uso mais concreto do verbo, as nuanças de sentido que a expressam se sobrepóem às da modalidade epistêmica, atestando, mais uma vez, que o isomorfismo semântico não está consolidado.

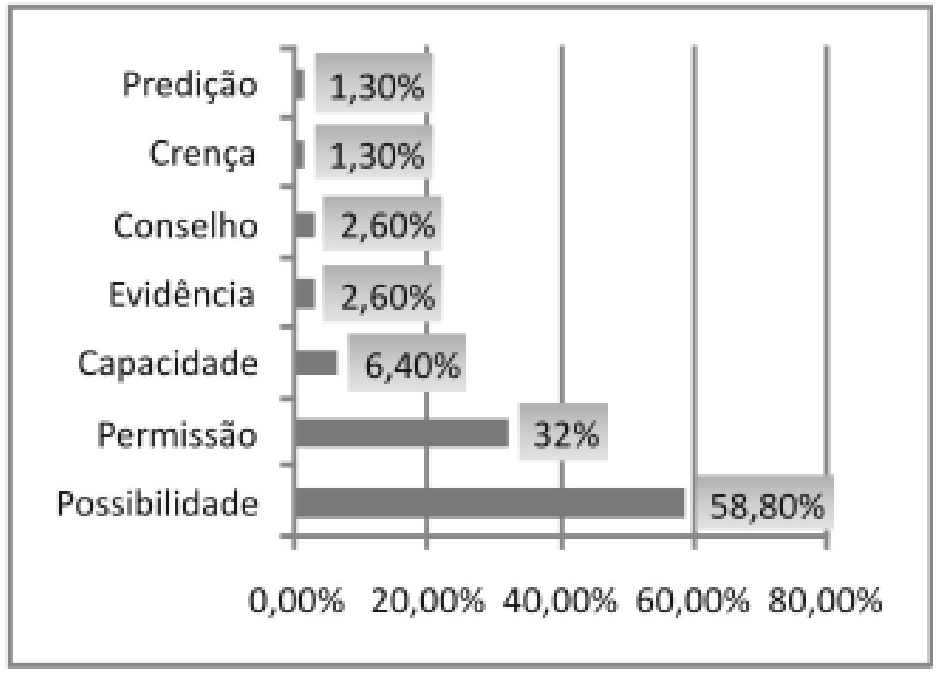

GRÁFICO 1: Possibilidades de interpretação semântica do verbo PODER Fonte: Dados coletados e analisados. 


\subsection{Análise de aspectos sintáticos do verbo PODER}

O terceiro critério de análise é de natureza sintática e buscou verificar se, tal como previsto pelos teóricos da gramaticalização, o verbo PODER, em virtude de seu já avançado estágio de gramaticalização, apresenta especialização de contexto sintático. Isso porque, conforme prevê o princípio da obrigatoriedade, proposto por Lehmann (1982), o avanço do processo de gramaticalização de um item resulta na redução dos seus contextos sintáticos e determina a sua maior previsibilidade, já que as formas tendem a se tornar mais fixas à medida que se deslocam do léxico para a gramática ou de uma posição menos gramatical para outra mais gramatical. Os dados analisados demonstraram que as perífrases modais constituídas com o verbo PODER formam-se exclusivamente com o infinitivo e que a variabilidade sintagmática do auxiliar em análise é bastante reduzida, o que confirma a relação proporcional entre o grau de gramaticalização e a fixidez da forma.

A literatura prevê ainda que, quanto mais avançado o processo de gramaticalização de uma forma perifrástica, maior a sua coesão e, consequentemente, menor a possibilidade de se intercalar qualquer tipo de material interveniente entre os elementos constituintes da perífrase. Mais uma vez, buscou-se julgar a pertinência desse postulado, testando-o contra os dados coletados. Em virtude de um processo de gramaticalização bastante antigo, era previsível que a coesão entre o verbo PODER e a forma nominal integrante da perífrase verbal fosse tão forte que não mais se registrasse a ocorrência de material interveniente entre seus constituintes, ou ao menos que houvesse uma redução significativa de tal ocorrência. O cômputo desses dados para o corpus do falar mineiro está apresentado na tabela 3 .

TABELA 3

Ocorrência de material interveniente nas perífrases

\begin{tabular}{c|c|c}
\hline Região / Século & $\begin{array}{c}\text { Ocorrência } \\
\text { de material } \\
\text { interveniente }\end{array}$ & $\begin{array}{c}\text { Ocorrência em } \\
\text { porcentagem } \\
(\%)\end{array}$ \\
\hline Ouro Preto / XVIII & 3 & 17,6 \\
Ouro Preto / XIX & 5 & 26,3 \\
Ouro Preto / XXI & 2 & 9,7 \\
Belo Horizonte / XXI & 3 & 8,7 \\
\hline
\end{tabular}

Fonte: Dados tabulados. 
A análise da tabela acusa uma redução da ocorrência de material interveniente entre os constituintes da perífrase, especialmente se compararmos o século XVIII (17,6\% de ocorrências) com o século XXI (9,7\% de ocorrências em Ouro Preto e $8,7 \%$ de ocorrências em Belo Horizonte), já que, no século XIX, registrou-se o maior índice percentual $(26,7 \%)$ para a ocorrência de material interveniente. A despeito da redução registrada entre os séculos XVIII e XXI, a ocorrência de material interveniente nas perífrases do século atual revela que o grau de coesão entre o auxiliar modal e o verbo principal ainda não é tão forte, principalmente se comparada à de outros auxiliares prototípicos. Os dados analisados acusaram ainda que o tipo de material interveniente presente nas perífrases do século XIX difere um pouco daquele identificado no século atual, conforme ilustram estes contextos:

(6) "[...] pode vm..$^{\text {ce }}$ vir ou mandar porellas [...]" (Ouro Preto, século. XVIII, grifo nosso).

(7) “[...] estou na circunstançia de não poder nem conservar aminha parte [...]" (Ouro Preto, século. XIX, grifo nosso).

(8) "[...] avossa senhoria podia ou não dispor de 3 fornos de ferro grandes [...]" (Ouro Preto, século. XIX, grifo nosso).

(9) “[...] não poder lhe dar até o prazo [...]" (Ouro Preto, século. XIX, grifo nosso).

(10) "Agenti num podi nem cunversa [...]" (Ouro Preto, século. XXI, grifo nosso).

(11) “[...] as colegas ais veiz podi até ti valê" (Ouro Preto, século. XXI, grifo nosso).

(12) "[...] ele veio assim pra podê... me, mim incomodá aqui [...]" (Belo Horizonte, século XXI, grifo nosso).

Uma perífrase em que se verificasse a presença de um pronome de tratamento ou mesmo de um pronome pessoal reto entre o auxiliar modal e a forma principal (cf. 6) teria sua gramaticalidade questionada nos dias de hoje, embora fosse aceitável no século XVIII. Há de se ponderar, contudo, a possibilidade de essa restrição não decorrer da gramaticalização do auxiliar PODER, mas de outro processo de mudança linguística. Alguns estudiosos (cf. TORRES MORAES, 
1993) atestam a alta frequência das ordens VSO e OVS no período arcaico. Segundo esses pesquisadores, a partir do século XVIII, entretanto, a ordem SVO passou a ser mais frequente. A construção expressa em (6) pode ser ainda um resquício desse processo de mudança linguística, o que descartaria uma possível relação da mudança do tipo de material interveniente com o processo de gramaticalização do auxiliar.

No tocante ainda aos contextos sintáticos, os dados coletados demonstraram que, no contexto específico de [PARA + INFINITIVO + (INFINITIVO) + INFINITIVO], oraçōes adverbiais finais, portanto, o verbo PODER está assumindo uma função expletiva, conforme ilustram estes enunciados:

(13) “[...] ela foi atrás de mim pra podê conversá comigo.” (Belo Horizonte, século XXI, grifos nossos).

(14) "Larguei, assim, a minha família pra podê i morá sozinho." (Belo Horizonte, século XXI, grifos nossos).

Tanto em (13) quanto em (14) a omissão do verbo PODER parece não alterar o enunciado quanto à expressão da finalidade, o que atesta o valor expletivo da forma nesses contextos. Ferreira (2000) também identificou essa estrutura em $46 \%$ das orações adverbiais finais analisadas. Ela partilha da interpretação expletiva atribuída ao PODER nesse contexto, mas pontua que "a retirada do verbo poder os torna excessivamente assertivos, o que significa dizer que o modal ainda tem uma contribuição semântica no enunciado" (p. 84, grifos da autora). A despeito da maior ou da menor assertividade do enunciado, esse é mais um indício de um processo de gramaticalização já consolidado, pois o verbo PODER, ao perder traços de significação, tornou-se tão abstrato a ponto de esvair os resquícios de seus semas que lhe facultavam a expressão da modalidade. Os dados coletados constituem indícios de que, nesse contexto específico, está iniciando um processo de discursivização, ou seja, o item está tramitando da gramática para o discurso, abdicando-se de suas funções gramaticais para assumir funções de marcador discursivo.

A análise dos contextos sintáticos será ainda evocada quando da análise da erosão fonética do verbo PODER, aspecto que será discutido na próxima subseção. 


\subsection{Análise da redução do material fônico}

A adoção de um critério fonético impõe algumas limitações a uma análise diacrônica, já que para os séculos XVIII e XIX trabalhou-se apenas com textos escritos, dado ser o acesso ao texto falado possível somente em períodos linguísticos mais recentes. Contudo, especialmente para este estudo, tal critério mostra-se relevante, uma vez que a erosão fonética de um item é mais facilmente percebida na modalidade falada da língua, a não ser que essa erosão já tenha se tornado tão expressiva a ponto de agregar-se a outro vocábulo, transformando o item gramaticalizado numa forma presa, como prevê o ciclo de gramaticalização.

Segundo Vitral e Ramos (2006), ao se gramaticalizar, o item sofre, além de alterações sintáticas e semânticas, alterações morfofonéticas decorrentes da “'redução' ou 'diminuição' de sílabas, sons e/ou acento" (p. 19). No tocante a esse aspecto, a análise dos dados do dialeto mineiro demonstrou que a tão censurada redução de pode para $p o$ 'só ocorre quando esse verbo se junta à forma nominal de infinitivo, para constituir uma locução verbal, conforme se observa em: "po'falá", "po' de(i)xá" e "po'fazê". Isso demonstra que tal redução é, portanto, resultante do fenômeno linguístico da gramaticalização, já que ela não ocorre quando o verbo se encontra em sua forma simples, ou plena, conforme se verifica em (15) e em (16), a seguir:

(15) a. Quem pode o muito pode o pouco.

b. * Quem $p o$ ' o muito $p o$ ' o pouco.

(16) a. Pode deixar em cima da minha mesa.

b. Po' de(i)xa em cima da minha mesa.

No tocante ainda às alterações morfofonéticas do item, buscou-se verificar também se, em decorrência da gramaticalização, o verbo PODER tornou-se mais fixo e, portanto, mais restritivo em relação à forma verbal com a qual se reduziria foneticamente ou se tal redução ocorre à revelia de fatores contextuais. O objetivo que norteou essa análise foi, portanto, verificar se a erosão fonética se dá independentemente da forma verbal com a qual o verbo PODER se junta para constituir a perífrase - o que constituiria um traço inerente ao falar mineiro - ou se ela é regida por fatores gramaticais e cientificamente explicáveis. Inicialmente, valendo-se da intuição de falante desse dialeto, selecionaram-se as formas passíveis de permitir a redução daquelas esperadas agramaticais, caso houvesse tal redução. Alguns dos contextos selecionados estão ilustrados na tabela 4: 
TABELA 4

Análise dos contextos de redução do verbo PODER

\begin{tabular}{|c|c|}
\hline $\begin{array}{l}\text { CONTEXTOS PASSÍVEIS } \\
\text { DE REDUÇÃO }\end{array}$ & $\begin{array}{l}\text { CONTEXTOS NÃO PASSÍVEIS } \\
\text { DE REDUÇÃO }\end{array}$ \\
\hline $\begin{array}{l}\text { "pode dar a todas hum prato de Sal bem } \\
\text { cheyo" (Ouro Preto, séc. XVIII) }\end{array}$ & $\begin{array}{l}\text { "De quantos modos pode ser considerada a } \\
\text { terra?" (Ouro Preto, séc. XIX) }\end{array}$ \\
\hline $\begin{array}{l}\text { "isto não tem e nem pode ter auctoridade } \\
\text { como escravos" (Ouro Preto, séc. XIX) }\end{array}$ & $\begin{array}{l}\text { "um dinheiro que pode ser investido em coisas } \\
\text { que pode ser auto sustentáveis né." (BH, séc XX) }\end{array}$ \\
\hline $\begin{array}{l}\text { "isto é, o genero humano, e tambem se lhe } \\
\text { pode chamar mundo (Ouro Preto, séc. XIX) }\end{array}$ & $\begin{array}{l}\text { "Cê tem qui ajudá, cê num podi isquenta a } \\
\text { cabeça também não." (Ouro Preto, séc. XXI)" }\end{array}$ \\
\hline $\begin{array}{l}\text { “pode comer quanto quiser” (Ouro Preto, séc. } \\
\mathrm{XIX} \text { ) }\end{array}$ & $\begin{array}{l}\text { "Vai chegá seu tempo. Ocê num podi i } \\
\text { avançandu assim não." (Ouro Preto, séc. XXI) }\end{array}$ \\
\hline $\begin{array}{l}\text { "Você pode contar um pouco do filme?" (BH, } \\
\text { séc. } \mathrm{XX})\end{array}$ & $\begin{array}{l}\text { "num si podi afirmar que seja verdadeiro" } \\
\text { (Ouro Preto, séc. XXI) }\end{array}$ \\
\hline
\end{tabular}

Fonte: Dados coletados.

Como demonstram os exemplos selecionados, a erosão fonética não é favorecida por todas as formas verbais que ocupam a segunda posição na locução verbal, o que atesta haver uma restrição dos contextos de erosão e, consequentemente, uma maior fixidez do verbo PODER gramatical. A redução não ocorre, por exemplo, quando a forma verbal com a qual o verbo PODER se liga para formar a locução verbal se inicia por som vocálico, nem por uma única sílaba, como é o caso do verbo ser, embora possa se reduzir com os verbos ter e dar. Entretanto, quando o segundo elemento da locução verbal se inicia por som oclusivo, fricativo ou lateral, parece haver uma forte tendência à redução.

Além dessa restrição contextual, que é de natureza fonética, acreditava-se que fatores morfossintáticos, como o tempo e o modo verbais, também favorecessem ou inibissem a redução. A hipótese inicial era de que a redução ocorreria apenas com a terceira pessoa do presente do indicativo (pode), restringindo-se a algumas formas principais, como já demonstrado: diz-se " $p o$ ' dá certo", mas não se diz "po’i(r) com ele", "pơ sê que dê certo". Entretanto, os dados da modalidade oral da língua suscitaram a possibilidade de esse contexto ser mais amplo, estendendo-se também à primeira pessoa do presente do indicativo (posso). Visando a verificar essa nova hipótese, procedeu-se a gravaçôes de falas dos contextos considerados prováveis e improváveis de redução e submeteram-se os 
dados a uma análise espectrográfica. A análise dos espectrogramas confirmou a intuição da perda sonora em perífrases constituídas com o verbo PODER flexionado na primeira pessoa do presente do indicativo, mas demonstrou tratarse de uma erosão distinta daquela constituída com o verbo na terceira pessoa. No caso de pode, que se reduz para po', ocorre uma haplologia, isto é, a perda de uma sílaba inteira. Em se tratando de posso, ocorre apenas a elisão da vogal subsequente ao [s], o que não é suficiente para descaracterizar a sílaba. Embora haja, do ponto de vista fonético, a perda da base silábica, não se configura, do ponto de vista fonológico, a perda da sílaba, o que pode ser comprovado pelo não vozeamento do fonema [s], como seria esperado, considerando-se o ambiente sonoro em que ele passa a ocorrer. O que se verifica no caso de posso é a manutenção do estatuto silábico, assegurado pelo alongamento do fonema [s]. A título de ilustração do que aqui se expõe, analisem-se os enunciados (17) e (18):

(17) Sua vida pós-bebêe [poz'bebê] não é mais a mesma.

(18) Eu não posso bebê [pos'bebê] hoje porque estou tomando antibiótico.

Em (17), o fonema [s] realiza-se como [z], por influência do contexto sonoro em que se encontra. Em (18), apesar de a elisão da vogal átona final favorecer a sonorização, já que se cria um ambiente sonoro tal como aquele presente em (17), o fonema [s] mantém-se não vozeado, o que demonstra que ele se alongou para preservar o estatuto silábico. Dessa forma, pode-se afirmar que a terceira pessoa favorece a perda da sílaba, enquanto a primeira pessoa permite apenas a redução do fonema final. Há de se considerar ainda que a redução da primeira pessoa, diferentemente daquela verificada para a terceira pessoa, parece não decorrer da gramaticalização do verbo, já que ela pode ser verificada em outras formas verbais não gramaticalizadas, como em (19):

(19) Não passa dentro [pas'dentrU] desse buraco que você (se) machuca.

A elisão da vogal átona final de formas verbais cuja última sílaba é constituída pelo fonema [s] é favorecida na língua por esse fonema e não pelo fenômeno da gramaticalização, o que confirma a hipótese inicial de que apenas a terceira pessoa permite a redução silábica. Outra especificidade da redução de posso é que, ao contrário do que ocorre com a terceira pessoa, o som vocálico inicial da segunda forma verbal constitui um contexto muito propício para a erosão fonética da primeira pessoa, já que se nota o apagamento da vogal final 
do verbo PODER, que passa a ser substituída na sílaba pela vogal inicial da forma verbal subsequente.

Diante das análises empreendidas, constatou-se que a erosão fonética do verbo PODER $\left(p o^{\circ}\right)$ em formas perifrásticas (ou locuçōes verbais) do dialeto mineiro não é apenas fruto de uma tendência linguística característica dessa região, mas resulta de seu processo de gramaticalização, que já se encontra em estágio bastante adiantado na língua. Dessa forma, acredita-se que a principal contribuição deste estudo resida no fato de desmistificar a crença tão alardeada pelo senso comum de que o mineiro é preguiçoso para falar e que, por isso, corta até sílabas inteiras de um vocábulo. Isso lhe rende inúmeras críticas, quando, na verdade, trata-se da atuação de um fenômeno linguístico muito produtivo e cientificamente explicável. Conforme detectado por este estudo, a erosão fonética que pode ocorrer na trajetória de uma forma plena a forma gramatical adquire uma configuração variável, não se processando, como toda mudança, de forma abrupta. Além disso, no caso do verbo estudado, ela não é aleatória, mas regida por critérios de natureza sintática - apenas quando o verbo PODER se liga à forma nominal de infinitivo, constituindo uma perífrase verbal , de natureza fonética-existem determinados segmentos que favorecem e outros que inibem a redução -, e de natureza morfológica - a forma de terceira pessoa do presente do indicativo favorece a redução.

\section{Considerações finais}

O fito para o qual se direcionou este estudo foi a análise do fenômeno linguístico responsável pela erosão fonética do verbo PODER quando este se junta ao infinitivo, para formar uma locução verbal, conforme se observa em "po' falá", "po' de(i)xá", "po' fazê".

Partiu-se da hipótese de que essa redução é resultante do fenômeno linguístico da gramaticalização e não um mero traço do falar mineiro que rende ao falante desse dialeto o atributo de "preguiçoso" e "desleixado". Tal hipótese fundou-se na constatação de que a redução ilustrada se restringe aos contextos de perífrase verbal, quando a forma já se encontra gramaticalizada. Os dados coletados atestaram a validade dessa hipótese, desmitificando a crença de que isso acontece porque o "mineiro tem mania de cortar pedaços de vocábulos." Percebeuse, por meio do estudo empreendido, que a erosão fonética é determinada por fatores de natureza sintática, fonética e morfológica. 
Além da precisão científica dos critérios que favorecem a redução do verbo PODER no dialeto mineiro, este estudo se propôs também a verificar o grau de gramaticalidade desse verbo no referido dialeto, mediante um cotejo diacrônico entre o falar ouro-pretano e o belo-horizontino. Os resultados obtidos demonstraram que, desde o século XVIII, as formas gramaticais do verbo PODER já se sobrepunham às suas formas lexicais e que as formas plenas se restringem a determinadas expressões bastante fossilizadas.

Outra generalização extraída das reflexões aqui tecidas relaciona-se à abstração por que vem passando o verbo PODER no estágio atual da língua. Os dados acusaram que, além da expressão gramatical da modalidade, esse verbo está desempenhando também funções discursivas, tornando-se, em contexto específico de INFINITIVO + (INFINITIVO) + INFINITIVO precedido da preposição PARA, uma partícula expletiva, o que resulta de seu alto índice de abstração. Tal abstração, certamente, é tributária de seu processo de gramaticalização de verbo pleno a auxiliar.

A despeito de os dados analisados terem fomentado várias elucubrações e, consequentemente, generalizaçôes, eles suscitaram também outras indagações. Acredita-se que os resultados encontrados sejam esclarecedores para a caracterização do falar mineiro, mas está-se consciente também de que ainda há muito por fazer. Esta pesquisa não esgotou as possibilidades de estudo deste aspecto, o que constitui uma das belezas de saber que o conhecimento não está pronto. Este não é, pois, um momento de fecho, mas de início de um novo investigar. Esperase que os resultados, bem como as generalizaçôes aqui alcançadas, motivem outros pesquisadores a se emaranharem pelas veredas linguísticas do falar mineiro.

\section{Notas}

${ }^{1}$ Um desses estudos é o Projeto Mineirês, desenvolvido pelo grupo de pesquisadores do NUPEVAR/UFMG, sob a coordenação da Profa. Dra. Jânia Martins Ramos e com recursos financeiros da FAPEMIG. Este trabalho é um subprojeto do Mineirês, desenvolvido no período de 2009 a 2010.

${ }^{2} \mathrm{O}$ termo gramaticalização, conforme será detalhado na seção 2 , é empregado neste estudo para se referir ao processo por meio do qual um item outrora de natureza lexical e, portanto, dotado de capacidade de referenciação externa, destitui-se de tal capacidade, para assumir funções linguísticas internas ou gramaticais, ou ainda para se referir ao deslocamento de um item de um estágio menos gramatical para outro mais gramatical. 
${ }^{3}$ Não se analisaram dados representativos do século XX, porque as entrevistas com falantes de Belo Horizonte e de Ouro Preto foram gravadas no início do século XXI, à medida que a pesquisa foi caminhando e os dados exigiram análise espectrográfica. Entretanto, tal procedimento não interfere na metodologia sociolinguística adotada, dado não haver transposto um período significativo de tempo, considerando-se a possibilidade de se trabalhar com dados de fala do fim do século XX.

4 "Antigamente, antes de habilitarem-se para casamento, os noivos tinham que apresentar certidão de batismo e certidão de banhos. Certidão de Banhos era um documento passado pelo pároco, do local de origem dos noivos, observando os prazos normais de publicação (3 dias), onde não poderia constar impedimento algum quanto ao casamento contratado, em outras palavras, o noivo ou a noiva não tinha feito promessa alguma de casamento que não fosse com aquela ou aquele. Portanto, a certidão de batismo e a certidão de banhos é que complementavam a habilitação de casamento, - não sendo a mesma coisa. No final do século XVIII, por exemplo, devido às dificuldades de comunicação, as certidões, tanto de batismo como de banhos, poderiam levar anos para chegar ao Brasil (quando chegavam). Neste período então, o noivo ou noiva deveria caucionar algum valor ou apresentar fiador, além de outras provas testemunhais de que o noivo ou noiva era quem se declarava filho ou filha daqueles pais, e que declarava que era solteiro ou solteira e que pelo que sabia, um ou outro não havia prometido casamento algum, que não havia parentesco nem compadresco entre eles, e que também não tinham feito voto de castidade ou de não casar. Em alguns casos, e sempre o noivo, desesperado para casar, mas sem dinheiro ou fiador, apresentava o que chamamos hoje de atestado de pobreza, - evidentemente com testemunhas de sua 'miséria'. Em algumas habilitaçôes, muito provavelmente por exigência do noivo, a noiva também se declarava 'virgem'." (FRANZEN, Renato. Disponível em: <http://reinodeclio. blogspot.com/2009/01/ certido-de-banhos.html>. Acesso em: 18 mar. 2010.)

${ }^{5}$ Nos dados de Ferreira (2000), também há registro de PODER lexical em contexto afirmativo, como verbo intransitivo ("Fulano tá podendo). Segundo a autora, são usos recentes cotejados na fala popular e "tudo indica tratar-se de um modismo que recupera este uso de poder [uso contextual mais antigo] também em enunciados afirmativos" (p. 86).

${ }^{6}$ Para informações mais detalhadas acerca dos traços diferenciadores do processo de gramaticalização dos referidos verbos, consultar Coelho e Vitral (2010).

${ }^{7}$ Segundo expõe Costa (2009), a modalidade deôntica envolve obrigação ou compulsão e tem, tipicamente, sua origem em regras morais ou sociais, numa autoridade, ou em alguma 'compulsão interna'. As origens dessa modalidade podem ser, portanto, externas ou internas ao sujeito obrigado, autorizado ou aconselhado a fazer alguma coisa. Essa modalidade envolve desejo, preferência, intenção, manipulação, capacidadel 
habilidadel, permissão/obrigação. Já a modalidade epistêmica está relacionada com o conhecimento e com a crença, em oposição ao fato. Geralmente sua origem é o falante, o qual conclui, com base em evidências, se a proposição é verdadeira ou falsa. Expressões epistêmicas são usadas para expressar o grau de comprometimento do falante com a verdade da proposição. Essa modalidade envolve, pois, verdade, probabilidade, certeza, crença, evidência, possibilidade.

${ }^{8} \mathrm{~A}$ análise total das ocorrências de PODER nesta tabela diverge daquela apresentada na tabela 1, porque aqui se computaram apenas as ocorrências em que poder exibia traços de modalidade.

${ }^{9} \mathrm{O}$ fato de o verbo PODER não se reduzir nas locuçôes com ser nem com ir, mas fazê-lo naquelas com o ter e o com o dar demonstra que não é o número de sílabas que está atuando para impedir a redução, mas o tipo de som inicial do segundo elemento da locução. Em ter, o som inicial é [t], que se distingue de [d], mesmo som inicial da sílaba suprimida, exclusivamente pelo traço da sonoridade.

\section{Referências}

CASTILHO, Ataliba T. de. A gramaticalização. Estudos Lingüisticos e Literários, Salvador, Universidade Federal da Bahia, n. 19, p. 25-63, mar. 1997.

COELHO, Sueli Maria. Estudo diacrônico do processo de expansão gramatical e lexical dos itens TER, HAVER, SER, ESTAR e IR na Lingua Portuguesa. 2006. 321f. Tese (Doutorado em Estudos Linguísticos) - Faculdade de Letras, Universidade Federal de Minas Gerais, Belo Horizonte, 2006.

COELHO; Sueli Maria; VITRAL, Lorenzo. O estatuto gramatical dos verbos relacionais. In.: VITRAL. L; COELHO, S. (Org.). Estudos de processos de gramaticalização em português: metodologias e aplicaçōes. Campinas: Mercado de Letras, 2010. p. 75-104.

COSTA, Sueli. Entre o deôntico e o epistêmico: o caráter camaleônico do verbo modal 'poder' Revista Eletrônica de Divulgação Científica em Lingua Portuguesa, Lingüistica e Literatura. Ano 5, n.11, $2^{\circ}$ semestre de 2009, ISSN 1807-5193.

FERREIRA, Lúcia Maria Alves. A estabilidade semântico-sintática do verbo PODER: evidências em três sincronias. 2000. 155 f. Tese (Doutorado em Linguística) Curso de Pós-Graduação em Letras, Universidade Federal do Rio de Janeiro, Rio de Janeiro, 2000.

FERREIRA, Lúcia Maria Alves. Evidências para uma abordagem pancrônica da mudança linguística e da estabilidade: o caso do verbo PODER. Diacrítica. Revista do Centro de Estudos Humanísticos. Universidade do Minho, 2010. p. 233-248. 
FRANZEN, Renato. Certidão de Banhos. Disponível em: <http://reinodeclio. blogspot.com/2009/01/certido-de-banhos.html>. Acesso em: 18 mar. 2010.

HOPPER, Paul. On some principles of grammaticalization. In: TRAUGOTT, E. C.; HEINE, B. (Org.). Approaches to grammaticalization. Amsterdam: John Benjamins, 1991. p. 59-90.

HOPPER, Paul J.; TRAUGOTT, E. Grammaticalization. Cambridge: Cambridge University Press, 1993.

KOCH, Ingedore Villaça. A inter-ação pela linguagem. 3. ed. São Paulo: Contexto, 1997. (Repensando a Língua Portuguesa).

LEHMANN, C. Toughts on grammaticalization: a programmatic sketch. Colônia: Arbeiten des Kölner Universalien Projects 48, 1982.

TORRES MORAES, M.A. Aspectos diacrônicos do movimento do verbo, estrutura da frase e caso nominativo no português do Brasil. In.: ROBERTS, I.; KATO, M. (Org.). Português brasileiro: uma viagem diacrônica. Campinas: Editora da Unicamp, 1993. p. 263-306.

VIANNA, Humberto Luiz Galupo. A estrutura modal + infinitivo em português: gramaticalização e modalização. 2000. 216 f. Dissertação (Mestrado em Estudos Linguísticos) - Faculdade de Letras, Universidade Federal de Minas Gerais, Belo Horizonte, 2000.

VITRAL, Lorenzo Teixeira. O papel da frequência na identificação de processos de gramaticalização. Scripta. Revista do Programa de Pós-graduação em Letras e do Centro de Estudos Luso-afro-brasileiros da PUC Minas. Belo Horizonte, 2005.

VITRAL, Lorenzo Teixeira; RAMOS, Jânia. Gramaticalização: uma abordagem formal. Rio de Janeiro: Tempo Brasileiro; Belo Horizonte: Faculdade de Letras da UFMG, 2006.

VOTRE, Sebastião. J. Cognitive verbs in Portuguese and Latin: unidirectionality revisited. Santa Barbara: Universidade da California, 1999. (mimeo).

VOTRE, Sebastião. J. A integração das objetivas diretas: a perspectiva pancrônica da integração função-forma na sintaxe do português. Cadernos do CNFL, 2, Rio de Janeiro: UERJ, 2000. p. 71-87. 